\title{
THOUGHTS ON THE PREVALENCE OF SYPHILIS *
}

\author{
By DOUGLAS WHITE, M.D.
}

Although the main object of this Journal is to promote knowledge of the nature and treatment of venereal diseases, it is also intended, from time to time, to cast a glance at the national and social aspects of these complaints. The forest is something more than the sum of its single trees: the presence of disease in mass opens up problems of a wider horizon than the treatment and cure of the individual case. It involves large questions of national, social, and legislative policy, towards which the medical mind should occasionally bend itself. But before we can tackle problems of public policy, we must first envisage, so far as may be, the quantity of the mischief now prevalent. This we are in a better position to measure, however tentatively, in terms of syphilis rather than of gonorrhoa. Our estimate of the latter will vary with that of the former.

The Royal Commission, in its Report (I9I6), concluded (p. 23, para. 68) that " the number of persons who have been infected with syphilis, acquired or congenital, cannot fall below Io per cent. of the whole population in the large cities." Now the larger towns (over 50,000 population) constitute about two-fifths of the population of Great Britain. If this portion be affected to the extent of Io per cent., the remaining three-fifths (on existing data) must be affected to not less than 5 per cent.; the sum works out at about two-and-a-half million persons infected with syphilis, acquired or congenital. Suppose now we assume that the half million represented all the cases of congenital syphilis at all ages, we should then be left with two million cases of acquired syphilis among the whole population of these islands. Since the average age of infection (as I have pointed out elsewhere) is about twenty-four to twenty-five, it is not reasonable to assume

* The writer wishes to express his indebtedness to Col. L. W. Harrison for valuable help and advice in the revision of this article. 
for infected persons a further expectation of life of more than thirty-three years. If then we divide our two millions by that number, we arrive at the figure of 60,000 annual infections; these would roughly be divided up between England, Scotland and Ireland in portions of $50,000,6,500$ and 3,500 respectively. This is, of course, only an interpretation of the Io per cent. general estimate.

Let us now turn to the actual figures which have come to light as the result of the free clinic system, instituted after the Royal Commission. A convenient summary of these results appeared on p. I3 of the January issue of this Journal. They show that in I920-the high-water mark of cases treated-nearly 43,000 new cases of syphilis were treated at the I9o centres in England and Wales; in I92I-22-23 the new cases of syphilis fell to 33,000, 26,000 and 24,000 respectively. In Scotland, the highest number of new cases of all sorts was I3,724 in I92I, and the lowest, I2,398, in I923; among the latter were 5,I76 cases of syphilis, as against 23,927 in England and Wales. The apparent fall, therefore, is much greater in England than in Scotland; but the conditions are dissimilar. The system of free clinics got into working order much earlier in England than in Scotland. The clinics in England were in a better position than those in Scotland to deal with the exceptional strain put upon them during the period of demobilisation. The present high efficiency in Scotland was gained rather later, and at first lagged behind the need. All over Britain there is no doubt that the amount of fresh venereal disease was exceptional. The next few years will probably show for Scotland a drop in new cases comparable to that in England since I920; already there has been a fall of Io per cent.

These figures for syphilis seem, at first blush, to confirm in a striking manner the Royal Commission's estimate. But it is necessary to make a further distinction; for, though the figures quoted from the English and Scottish clinics were new cases, they were by no means all fresh cases ; a large proportion of the new cases in England (I923)-nearly 6o per cent., judging by the experience in one very large centre-were cases of longer than a year's standing. So, for that year-the latest for which we have returns-the fresh cases were probably not 


\section{BRITISH JOURNAL OF VENEREAL DISEASES}

much more than I0,000, while on a similar basis Scotland would only yield 2,000. But what proportion of actual fresh infections is represented by this I2,000? A considerable number, of course, are dealt with in private practice, and there is doubtless a number who are not treated at all. One does not want to under-estimate such cases, for they must be an important factor. Yet syphilis has been recognised for many years past by the public as a serious complaint ; it is the "bad disorder," and the process of education in the last eight years has still further enhanced the dread of syphilis. There must, indeed, be many cases of syphilis where ignorance or shame operate towards concealment, specially where the early symptoms are mild. It seems, however, unlikely, on the whole, that the actual number of fresh infections will be more than twice the number that appear at the clinics. If that is considered a fairly liberal allowance, then we might conclude that the fresh cases of syphilis for each year in Great Britain do not at present number more than about 25,000. There can be no doubt that the clinics have reduced the numbers of infections to a large extent; the English figures suggest a fall of over 40 per cent. It is by no means impossible that the estimate of the Royal Commission may have been fairly correct for the pre-war incidence. Syphilis, in spite of a wartime exacerbation, has been undergoing a steady reduction during the last forty years; in the home army its incidence has dropped to one-tenth of what it was in I885; among civilians the reduction cannot be nearly so great, but it has been wonderfully speeded up by the system of organised treatment and education ; a further diminution of the annual incidence may be confidently expected.

Perhaps a note of caution is required. For if it be true that the annual incidence is reduced to something like 25,000 , yet it does not follow that the total number of syphilitics is falling off rapidly. Syphilis is a chronic complaint, and many of those who contracted it in its more exuberant period are still alive. The syphilitic population may be analogous to the total general population-diminished annual additions, but not therefore a diminished total.

Perhaps one word may here be said about gonorrhœa. The " new " cases of this malady are keeping pretty level 


\section{THOUGHTS ON THE PREVALENCE OF SYPHILIS}

at about 30,000, while those of syphilis are decreasing $(23,927$ in I923); but experience seems to indicate that nearly two-thirds of the new cases of gonorrhœa are also fresh cases. This means that the fresh cases of gonorrhœa in I923 were to the fresh cases of syphilis as $2 \frac{1}{2}$ to $I$, which is approximately the proportion in which infections with the two diseases are believed to prevail. This is so far satisfactory, though the statistics seem to show that women are not using the clinics nearly so much in proportion to the probable numbers infected as are the men. This is doubtless largely due to the relative mildness of symptoms in women, with consequent non-recognition.

\section{Tabes and General Paralysis of Insane}

The best index that we possess of the progress or regress of syphilis in the country is afforded by the mortality figures from tabes and G.P.I. For many years past the incidence of these in England and Scotland has been closely proportional to the populations. Therefore, in considering them we may conveniently take England and Scotland together. Since tabes and G.P.I. are closely related, being respectively spinal and cerebral manifestations of syphilis - often indeed inter-associated - it might seem reasonable also to take them together. But there are differences which we must not neglect.

The age of maximum mortality from G.P.I. seems to be about forty-five or, in the case of men, rather earlier ; death occurs, as a rule, within three years of onset ; it is longer delayed in tabes, where the maximum age of mortality is nearer fifty-five. Now the maximum age for acquisition of syphilis is not later than twenty-five. Therefore, where there is a considerable rise or drop in the acquisition of syphilis, we should not expect to find the change fully reflected in the mortality returns from G.P.I. and tabes for a considerable number of yearslonger in the case of tabes than of G.P.I. But we should expect to see the beginning of that reflexion within ten years of an actual drop in syphilitic infection. Now, in fact, there is already a very considerable drop in the recorded mortality from G.P.I. (England and Scotland). From I9OI-I 8 there was a steady average of 2,500 (varying between 2,300 and 2,650); in I9I9 there was a sudden drop, with an average, from I9I9-23, of $I, 830$, represent- 


\section{BRITISH JOURNAL OF VENEREAL DISEASES}

ing an average fall of 27 per cent. No such decrease has shown itself for tabes, the figures of which have been pretty steady for ten years past at about 800 ; perhaps the time has not yet come for such a decrease to appear. In aneurysm, the last eight years have shown an average decrease of I2 per cent., not well maintained, but in reasonable conformity with the curve of G.P.I., though less accentuated. It will be at least several more years before we can pronounce a solid judgment as to the effects of the War ; all we can say at present is, that the indications are favourable, with good hopes that the diminished G.P.I. will continue, and that tabes (and.also aneurysm) may follow suit.

It is, however, peculiar, that while the G.P.I. mortality (as already shown) was steady in actual numbers during the first eighteen years of the century, and fell greatly in the next five years, tabes, in the first twelve years, gradually rose from 500 to a level of 800 , so that the numerical ratio of tabes to G.P.I. has risen from I : 5 at the start of the century to more than $I: 2.5$ at present. We have yet to find out what circumstance or peculiarity determines the victim of syphilis towards tabes or G.P.I., or what sort of strain tends to break down one portion of the nervous system rather than another. As regards the proportion of syphilitics who develop one or other of these forms of neurosyphilis, the most recent work which I know is that of Mattauschek and Pilcz (Vienna), on the history of 4 ,I34 officers who contracted syphilis, of whom $7 \cdot 5$ per cent. developed either tabes or G.P.I. (see Appendix to First Report of Royal Commission, Q. IoI85 ff.). This is a higher proportion than was previously thought probable.

\section{Sex Distribution of Syphilis}

What is the proportion in this country of men and women affected with syphilis? At first sight the figures for tabes, G.P.I. and aneurysm seem to give us the answer, for, taken all together over the last twenty-four years, these complaints show a mortality of nearly five men to one woman. In G.P.I. the ratio has undergone a change in this century; at the beginning the female-male ratio was $I: 3$; now it is little more than I : 5 . In tabes the women's proportion, both at the beginning and end of the period, stood at $I: 5$, but in the years I9I5-20 it fell 


\section{THOUGHTS ON THE PREVALENCE OF SYPHILIS}

as low as $I: 6$ or even $I: 7$. In aneurysm the ratio has been fairly steady at $I: 4$ throughout. At the present time, we may take it that, for every hundred men affected with tabes or general paralysis, only about twenty-one women are affected; in aneurysm about twenty-six.

But we are confronted with another set of figures, namely, the registered deaths from "syphilis " in adults ; these show a very different ratio, viz., about seventeen men to ten women. It may be truly said that these figures are unreliable, representing, as they do, only a small fraction of the deaths due to this cause. Indeed, how small a fraction may be judged from the fact that, while some 2,500 per annum (formerly 3,000) die from tabes and G.P.I. (England and Wales), another I,000 from aneurysm, and (to take one other example) some 3,000 adults below fifty die from cerebral hæmorrhage, yet syphilis is only given as the cause of death in some 500 or 600 cases. Nevertheless, such as it is, this fractional index of syphilitic deaths has a real significance; it has been remarkably steady in sex-ratio over many years, and it cannot be neglected as a small-scale representation of the facts. It is, no doubt, possible that a greater number of male than of female deaths are concealed, owing to the lower social status of many of the females concerned; but (as Dr. T. H. C. Stevenson says) this can hardly account for the discrepancy, except to a small degree. Moreover, the clinics show, among syphilitics attending them, a male-female ratio of less than 2 to $I$, and this tending to decrease. Of the women attending, some, doubtless, are only discovered as syphilitic owing to the children whom they bring with them; but their greater immunity to early manifestations points to a larger number of women being actually syphilitic than their symptoms show; hence the real proportion of women to men may be higher than the statistics disclose.

The above-mentioned highly divergent ratios are obviously difficult to reconcile ; but there are considerations which may help us. There seems to be evidence that syphilis is a milder disease in women than in men, and that this is specially true of parous women during the child-bearing ages. A woman may repeatedly bear syphilitic infants though she herself suffers from no clinical symptoms. Most women who acquire syphilis acquire it either before marriage at ages eighteen to twenty, or 


\section{BRITISH JOURNAL OF VENEREAL DISEASES}

shortly after marriage ; the acquisition is largely accompanied by pregnancy, the effect of which may be to protect the central nervous system. In somatic developments, however, the relative immunity may tend to pass away with advancing age, so that the incidence of deaths from somatic syphilis may show a truer male-female ratio than those arising from cerebro-spinal involvement. Another partial explanation of the relative infrequency of these forms of neuro-syphilis in women may be that the nervous system of women is less liable to continuous strain than that of men-the brain of brain-workers, the spinal system of manual labourers. Similarly, it may be that a persistently high blood pressure (induced by manual labour) may determine aneurysm with greater frequency in syphilitic men than women. On the whole, I now incline to believe that the ratio of syphilitic infection, as between men and women, is probably not greater than two to one ; the relative infrequency of cerebro-spinal involvement in women being due to the milder character of their disease.

\section{Congenital Syphilis}

The death rate from syphilis of male infants has for the last twelve years exceeded that of females by about 35 per cent. ; this is a higher excess than in the previous decade, and higher than in infant deaths from most diseases. In the years I9Io-2I (England and Wales) I 4,877 children were registered as dying from "syphilis" in the first year of life-an average of 1,240 a year. For the previous ten years the numbers were slightly less, about I,I8o. The War was probably the main cause of rather higher figures during the years I9I4-2I (highest I,443 in I920); following on this, the years I922-23 exhibit a very remarkable fall, the totals being 874 and 797. This is the most encouraging feature of the whole situation, suggesting a clear drop of about 30 per cent. Scotland shows a simultaneous reduction, though not so great. The death rate also, per thousand born alive, has fallen from 2.03 in I9I7 (an unusually high figure) to $I \cdot 05$ in I923-far the lowest of any recent years. Yet, gratifying as is the reduction of recorded infant deaths from this cause, they are only, as in the case of adults, a small fractional index of the truth. They are, as it were, a fairly constant sample. We do not 


\section{THOUGHTS ON THE PREVALENCE OF SYPHILIS}

know, even vaguely, the number of infants born each year with congenital syphilis, nor the proportions of them who die or survive.

We require to know (I) what percentage of mothers are syphilitic, and (2) what proportion of their live-born children are syphilitic. As to the first of these, Cruickshank has recently published a paper * in which he finds (as a result of a large series of W.R.'s) that of Glasgow mothers of the hospital class, 9 to ro per cent. are syphilitic. Such a figure is, of course, a good deal higher than we should expect to find in the general population; yet the fact is distinctly arresting. On the other hand, the same author finds (again by W.R.) that the proportion of children born alive to these women, with a persistently positive reaction, is exceedingly small. He finds (with Fildes) that the great majority of infants born with a positive W.R. become negative within a few weeks or months, so that the results based on the W.R. of newlyborn infants are unreliable. If, then, a later negative W.R. in infants be taken to indicate freedom from syphilis (at least in most cases), Cruickshank's results would seem to imply (as I read them) that of children born alive to syphilitic mothers, only about one in twelve is truly syphilitic. From his figures he reasonably concludes that only I per cent. or less of the total live births in the community are syphilitic. If this be happily true, then only about 8,000 live syphilitic children are now born annually in this country. But it must be admitted that such a finding is not in accord with most of the previous observations and estimates. In the U.S.A. the most accepted estimates give figures varying from 3.5 per cent. to 5 (or more) per cent. of syphilis in the infant population; though, even if such an estimatesay 4 per cent.- - were true for the United States, it would by no means follow that a like estimate would hold good here.

Suppose now we start with the finding that io per cent. of mothers of the hospital class in Glasgow are infected ; if this holds good of other great cities we might perhaps expect to find 6 per cent. of mothers throughout the country so infected. If the children of these mothers were all syphilitic, and in proportional numbers to

* Medical Research Council. "Maternal Syphilis as a Cause of Death of Fœtus and New-born Child." J. N. Cruickshank. I924. 


\section{BRITISH JOURNAL OF VENEREAL DISEASES}

children of healthy mothers, clearly 6 per cent. of all infants would be syphilitic. But since a much greater proportion of them are born dead, the percentage of live syphilitic children would certainly not be more than 5 per cent., even if we assumed that all the live children of syphilitic mothers were themselves syphilitic. What we need is to know the proportion of such children who are in fact syphilitic. I suspect that the estimate of one in twelve is much too low, in view of past clinical experiences of many reliable authors. For instance, Jeans (U.S.A.), in a series of Ioo pregnancies of syphilitic women, found 39 abortions or still-births ; $*$ of the remaining 6I, 24 died later (40 per cent.). Harman, among $I$,ooo pregnancies in syphilitic families, found $I 7$ per cent. abortions or still-births, 23 per cent. died later, 2I per cent. living but syphilitic, and 39 per cent. healthy (= 47 per cent. of the live-born). Veeder found that, out of 33I pregnancies of Ioo syphilitic mothers, there were only 200 live children, of whom 39 had died; of the I6I remaining, I07 were both clinically and serologically syphilitic, 2I either one or the other, while only 33 were healthy-one in six of live-born children. In face of such figures, it is hard to believe that only an inconsiderable fraction of live-born children of syphilitic mothers are themselves (apart from treatment) syphilitic; and, although we are bound to admit (as a very general proposition) that the danger to children decreases as the mother's infection becomes less recent, yet there are cases on record of syphilitic offspring where the mother's infection was over twenty years old, and in one recorded case, thirty-seven years (infection in childhood). On the whole, we may perhaps deem it improbable that, of children born alive in this country (as a whole), less than I per cent. or more than 3 per cent. are born syphilitic. Each unit per cent. represents some 8,500 children annually.

But, after all, it is not a static question; nor does it matter so much what number of syphilitic children were born last year or the year before. The urgent point is that syphilis of the newborn can be actually prevented in the great majority of cases by vigorous and sufficiently early antenatal treatment. In illustration let me quote two

* Eardley Holland finds, among 300 still-births, 16 per cent. were due to syphilis. This is a smaller proportion than previously supposed. ("Causation of fœtal death." Ministry of Health. I922.) 


\section{THOUGHTS ON THE PREVALENCE OF SYPHILIS}

series of cases. Boas and Gammeltoft found that among I58 untreated mothers (half suffering from secondary and half from latent syphilis) only one had a healthy child; at the other end of the scale, of seven mothers treated with salvarsan both before and during pregnancy, six had healthy children. They quote Sauvage as giving a similar experience, viz., 85 per cent. syphilitic births where the mothers had no (or irregular) treatment, and 85 per cent. of healthy births with vigorous treatment. The very high figures of morbidity are practically reversed.* It is notable also that Boas and Gammeltoft conclude that every syphilitic woman should be treated with salvarsan during every pregnancy, no matter how old the infection, nor how efficiently the mother has been treated before, nor whether her W.R. is positive or negative. A similar view is propounded by other authorities, both here and in America.

The urgency of antenatal care is too well recognised to need stressing, not only in syphilis but in all conditions; I would only suggest that the most important period is in the earliest rather than the later months of pregnancy ; the future of the babe is largely determined in the earliest period of its development; the condition and nutrition of a woman at the time of conception is of prime importance. This fact is not stressed by the medical profession as it ought to be, nor is it understood even by well-educated parents.

But perhaps in this I am overstepping the limits of my theme; for this paper was intended only to give some ideas concerning the incidence of syphilis. I hope my remarks have been suggestive without dogmatism. In forming any sort of estimate, one must always remember that syphilis is a disease of variable intensity, not only in different countries, but in the same country at different times; I have never forgotten the remark of my shrewd and venerable examiner at the College of Surgeons: "My boy, you don't see syphilis now as we saw it forty years ago."

* J. W. Ballantyne illustrates the same from the still-birth records in Fdinburgh (I92I). The rate of still-birth in untreated syphilitic women was 606 per 1,000 ; in women who had received treatment, $5^{\circ} \cdot 7$ per 1,000 ; for the non-syphilitic antenatally. supervised, 5.9 per I, ooo. 